\title{
The Development of Higher Education in Northeast Three Provinces of China
}

\author{
Xiaoshu Wang ${ }^{\mathrm{a},{ }^{*}}$ and Le Wang ${ }^{\mathrm{b}}$ \\ Bohai University, Jinzhou, Liaoning, China \\ a49718990@qq.com, blewang1982@163.com
}

\begin{abstract}
Keywords: Higher Education; University; Teachers and Students; Northeast China
\end{abstract}
\begin{abstract}
Northeast China is a geographical region of China, the development of higher education is crucial to the economic and social development of Northeast China. This paper use the data from China Statistical Yearbook to analyze the development of higher education in Northeast China in recent years, analyzed the proportion of Northeast China to the whole country, and also compared the three northeast provinces. The result shows that, from 2000 to 2015, the higher education of Northeast China has improved a lot. The number of universities and colleges in Northeast China has increased from 133 to 255; the number of university teachers has increased from 146640 to 237053 ; and the number of undergraduate students on campus has increased from 699096 to 2373524 . In the proportion of Northeast China to the whole country, the proportion of universities and colleges of Northeast China to the whole country has decreased from $12.78 \%$ to $9.96 \%$; the proportion of number of teachers has decreased from $13.18 \%$ to $10.01 \%$; and the proportion of number of undergraduate students on campus has decreased from $12.57 \%$ to $9.04 \%$. In the comparison of the three northeast provinces, on the indicator of proportion of numbers of universities and colleges, teachers and undergraduate students on campus, Liaoning province always takes over $40 \%$ of Northeast China, Jilin province is about $25 \%$, and Heilongjiang province is about $35 \%$.
\end{abstract}

\section{Introduction}

Northeast China is a geographical region of China. It consists specifically of the three provinces of Liaoning, Jilin and Heilongjiang. Northeast China is the cradle of Chinese industry, and has obvious geographical advantages, abundant resources and great potential for development. ${ }^{[1]}$

The development of higher education is crucial to the economic and social development of Northeast China. There are many universities and research institutes located in this area, such as Harbin Institute of Technology, Jilin University, Dalian University of Technology, Northeastern University, Liaoning University, and institutions from Chinese Academy of Sciences, such as Dalian Institute of Chemical Physics, Shenyang Institute of Metal Research, Shenyang Institute of Applied Ecology, Changchun Institute of Optics, Fine Mechanics and Physics and so on. ${ }^{[2-9]}$

This paper use the data from China Statistical Yearbook ${ }^{[10]}$ to analyze the development of higher education in Northeast China in recent years, analyze the proportion of Northeast China to the whole country, and also compare the three northeast provinces.

\section{The Development of Higher Education in Northeast China in Recent Years}

The Number of Universities and Colleges. From 2000 to 2015, the number of universities and colleges in Northeast China has increased from 133 to 255; it is nearly two times of the original. From 2000 to 2010, the number increased very fast, but in recent 5 years, Northeast China only increased 8 universities and colleges (refer with: Fig. 1). 


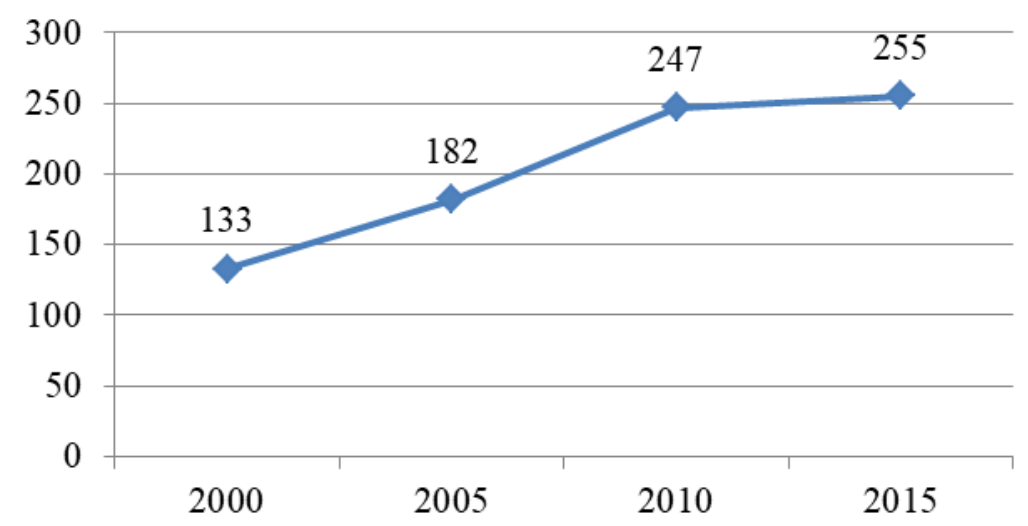

Figure 1. The number of universities and colleges in Northeast China

The Number of University Teachers. From 2000 to 2015, the number of university teachers in Northeast China has increased from 146640 to 23705 (including full-time teacher, administrative staff, support staff, and service staff), increased by 61.66\%. From 2000 to 2010, the number of teachers also increased very fast, in recent 5 years, the growth is slowdown (refer with: Fig. 2).

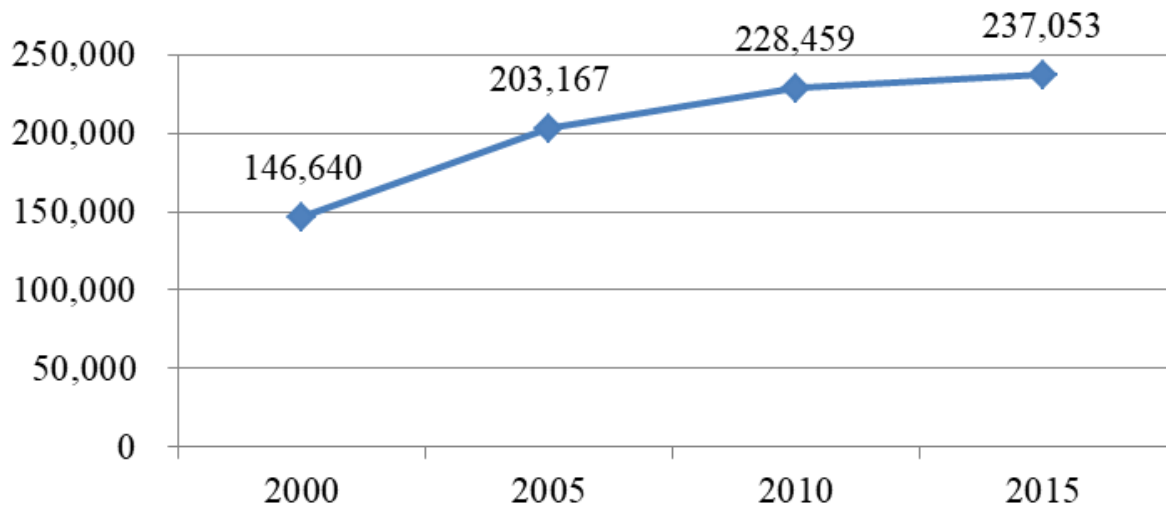

Figure 2. The number of university teachers in Northeast China

Distribution of Full-Time Teachers' Titles. Full-time teachers' titles include professor, associate professor, lecturer, teaching assistant and non-professional titles. The numbers and distribution of full-time teachers' titles is listed in Table 1 and Table 2. (No data in 2000)

Table 1 The number of full-time teachers' titles

\begin{tabular}{|l|r|r|r|c|}
\hline Title & 2005 & 2010 & 2015 & Changed in 10 years \\
\hline Professor & 12552 & 18529 & 22686 & $+80.74 \%$ \\
\hline Associate professor & 33814 & 41273 & 48164 & $+42.44 \%$ \\
\hline Lecturer & 32299 & 50368 & 61109 & $+89.20 \%$ \\
\hline Teaching assistant & 23713 & 21326 & 14679 & $-38.10 \%$ \\
\hline Non-professional & 4838 & 4088 & 4499 & $-7.01 \%$ \\
\hline
\end{tabular}

Table 2 The distribution of full-time teachers' titles (\%)

\begin{tabular}{|l|r|r|r|c|}
\hline Title & 2005 & 2010 & 2015 & Changed in 10 years \\
\hline Professor & 11.71 & 13.67 & 15.01 & $+3.30 \%$ \\
\hline Associate professor & 31.54 & 30.44 & 31.87 & $+0.33 \%$ \\
\hline Lecturer & 30.13 & 37.15 & 40.43 & $+10.31 \%$ \\
\hline Teaching assistant & 22.12 & 15.73 & 9.71 & $-12.40 \%$ \\
\hline Non-professional & 4.51 & 3.02 & 2.98 & $-1.54 \%$ \\
\hline
\end{tabular}


The Numbers of Undergraduate Students on Campus. In the absence of statistics on graduate students, this section examines only undergraduate students. From 2000 to 2015, the number of undergraduate students on campus in Northeast China has increased from 699096 to 2373524 , increased by $239.5 \%$. (refer with: Fig. 3 ).

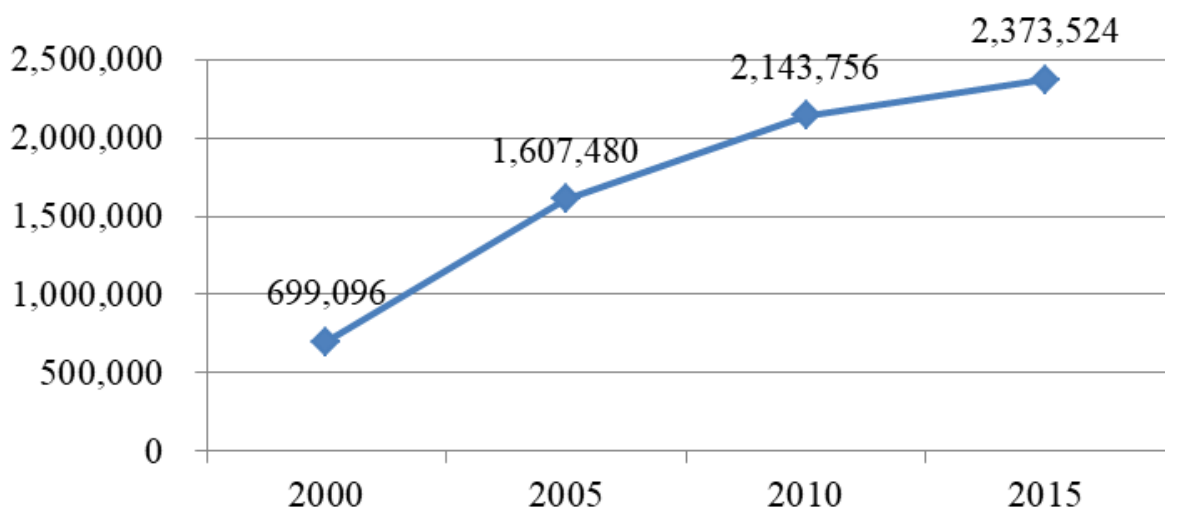

Figure 3. The number of undergraduate students on campus in Northeast China

\section{The Proportion of Northeast China to the Whole Country}

The Proportion of Number of Universities and Colleges. From 2000 to 2015, the number of universities and colleges in China has increased from 1041 to 2560. The proportion of universities and colleges of Northeast China to the whole country has decreased from $12.78 \%$ to $9.96 \%$, it means the growth speed of the number of universities in the whole country is more faster than the Northeast China (refer with: Fig. 4).

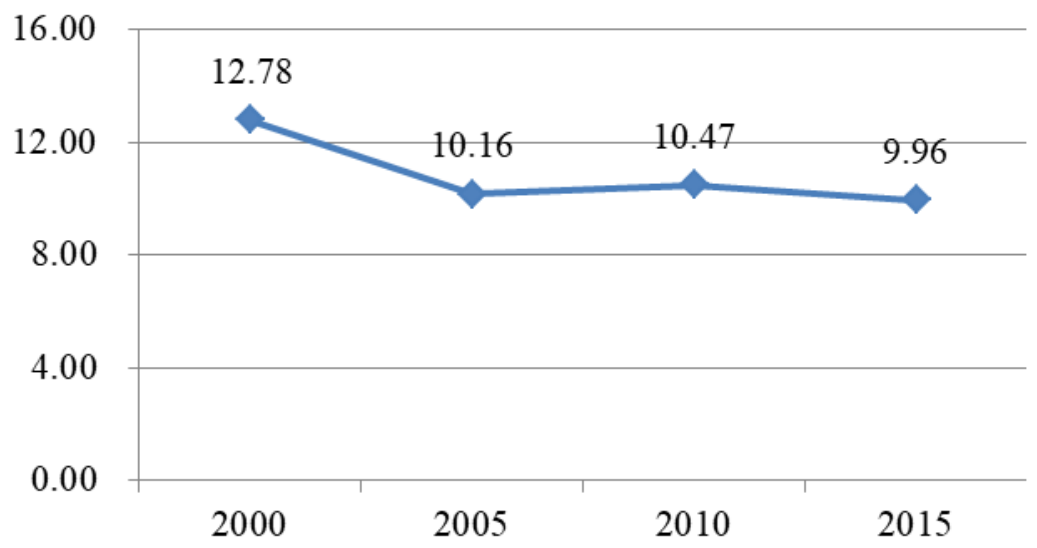

Figure 4. The proportion of universities and colleges of Northeast China to the whole country (\%)

The Proportion of Number of Teachers. From 2000 to 2015, the number of teachers in China has increased from 1112776 to 2369326 (including full-time teacher, administrative staff, support staff, and service staff). The proportion of number of teachers of Northeast China to the whole country has decreased from $13.18 \%$ to $10.01 \%$, so the growth speed of the number of teachers of Northeast China is less than the whole country (refer with: Fig. 5). 


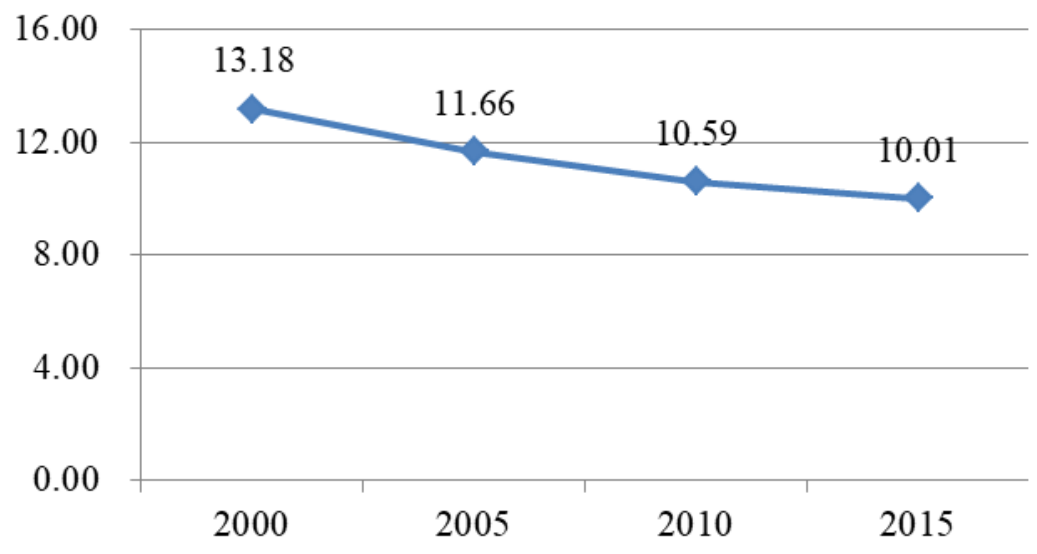

Figure 5. The proportion of teachers of Northeast China to the whole country (\%)

The Proportion of Number of Undergraduate Students on Campus. From 2000 to 2015, the number of undergraduate students on campus in China has increased from 5.56 million to 26.25 million. The proportion of number of undergraduate students on campus of Northeast China to the whole country has decreased from $12.57 \%$ to $9.04 \%$, so the growth speed of the number of undergraduate students on campus of Northeast China is less than the whole country (refer with: Fig. 6).

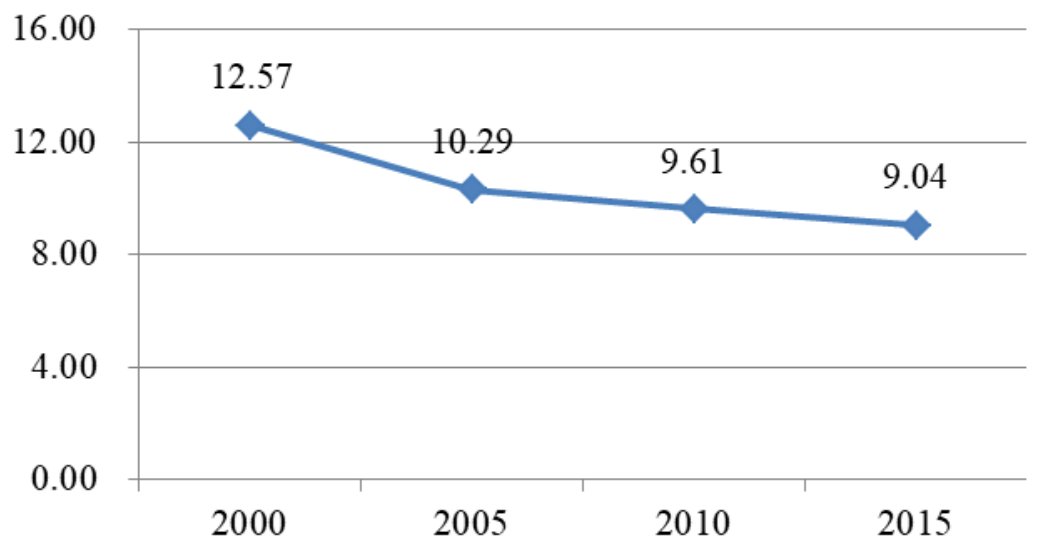

Figure 6. The proportion of undergraduate students on campus of Northeast China to the whole country $(\%)$

\section{The Comparison of the Three Northeast Provinces}

The Comparison of Number of Universities and Colleges. The numbers of universities and colleges in three northeast provinces are listed in Table 3. From 2000 to 2015, the numbers of universities and colleges are all increased in the three provinces. Liaoning increased 52 universities and colleges, increased by $81.25 \%$; Jilin increased 24 universities and colleges, increased by $70.59 \%$; Heilongjiang increased 46 universities and colleges, increased by $131.43 \%$.

Table 3 The comparison of number of universities and colleges in three northeast provinces

\begin{tabular}{|l|r|r|r|r|r|r|}
\hline Province & 2000 & 2005 & 2010 & 2015 & Increased number & Changed in 15 years \\
\hline Liaoning & 64 & 76 & 112 & 116 & 52 & $+81.25 \%$ \\
\hline Jilin & 34 & 44 & 56 & 58 & 24 & $+70.59 \%$ \\
\hline Heilongjiang & 35 & 62 & 79 & 81 & 46 & $+131.43 \%$ \\
\hline Total & 133 & 182 & 247 & 255 & 122 & $+91.73 \%$ \\
\hline
\end{tabular}

The reason of low growth of Jilin is the university merger. In 2000, Jilin University merged with the former Jilin University of Technology, the former Norman Bethune University of Medical Sciences, the 
former Changchun University of Science and Technology and Changchun Institute of Posts and Telecommunications. In 2004, the former University of Military Logistics also joined. ${ }^{[4]}$

The proportion of three provinces is listed in Table 4. Liaoning province is all over $40 \%$, Jilin province is about $25 \%$, Heilongjiang province is about $35 \%$.

Table 4 The proportion of numbers of universities and colleges in three northeast provinces $(\%)$

\begin{tabular}{|l|r|r|r|r|r|}
\hline Province & 2000 & 2005 & 2010 & 2015 & Changed in 15 years \\
\hline Liaoning & 48.12 & 41.76 & 45.34 & 45.49 & -2.63 \\
\hline Jilin & 25.56 & 24.18 & 22.67 & 22.75 & -2.82 \\
\hline Heilongjiang & 26.32 & 34.07 & 31.98 & 31.76 & +5.45 \\
\hline Total & 100 & 100 & 100 & 100 & - \\
\hline
\end{tabular}

The Comparison of Number of Teachers. The numbers of teachers (including full-time teacher, administrative staff, support staff, and service staff) in three northeast provinces are listed in Table 5. From 2000 to 2015, the numbers of teacher are all increased in the three provinces. Liaoning increased by $58.69 \%$; Jilin increased by $50.77 \%$; and Heilongjiang increased by $76.45 \%$.

Table 5 The comparison of number of teachers in three northeast provinces

\begin{tabular}{|l|r|r|r|r|r|r|}
\hline Province & 2000 & 2005 & 2010 & 2015 & $\begin{array}{r}\text { Increased } \\
\text { number }\end{array}$ & $\begin{array}{r}\text { Changed } \\
\text { in } 15 \text { years }\end{array}$ \\
\hline Liaoning & 61707 & 82816 & 93183 & 97924 & 36217 & $+58.69 \%$ \\
\hline Jilin & 41813 & 54689 & 59535 & 63043 & 21230 & $+50.77 \%$ \\
\hline Heilongjiang & 43120 & 65662 & 75741 & 76086 & 32966 & $+76.45 \%$ \\
\hline Total & 146640 & 203167 & 228459 & 237053 & 90413 & $+61.66 \%$ \\
\hline
\end{tabular}

The proportion of three provinces is listed in Table 6. Liaoning province is all over $40 \%$, Jilin province is about $25 \%$, Heilongjiang province is about $35 \%$.

Table 6 The proportion of numbers of teachers in three northeast provinces (\%)

\begin{tabular}{|l|r|r|r|r|r|}
\hline Province & 2000 & 2005 & 2010 & 2015 & Changed in 15 years \\
\hline Liaoning & 42.08 & 40.76 & 40.79 & 41.31 & -0.77 \\
\hline Jilin & 28.51 & 26.92 & 26.06 & 26.59 & -1.92 \\
\hline Heilongiang & 29.41 & 32.32 & 33.15 & 32.10 & +2.69 \\
\hline Total & 100 & 100 & 100 & 100 & - \\
\hline
\end{tabular}

The Comparison of Number of Undergraduate Students on Campus. The numbers of undergraduate students on campus in three northeast provinces are listed in Table 7. From 2000 to 2015, the numbers of undergraduate students on campus are all increased a lot in the three provinces. Liaoning increased by $226.58 \%$; Jilin increased by $249.53 \%$; and Heilongiiang increased by $249.83 \%$, the increased ratio are very close.

Table 7 The comparison of number of undergraduate students on campus in 3 northeast provinces

\begin{tabular}{|l|r|r|r|r|r|r|}
\hline Province & 2000 & 2005 & 2010 & 2015 & $\begin{array}{r}\text { Increased } \\
\text { number }\end{array}$ & $\begin{array}{r}\text { Changed } \\
\text { in 15 years }\end{array}$ \\
\hline Liaoning & 307931 & 659351 & 880247 & 1005650 & 697719 & $+226.58 \%$ \\
\hline Jilin & 181019 & 407262 & 544392 & 632723 & 451704 & $+249.53 \%$ \\
\hline Heilongjiang & 210146 & 540867 & 719117 & 735151 & 525005 & $+249.83 \%$ \\
\hline Total & 699096 & 1607480 & 2143756 & 2373524 & 1674428 & $+239.51 \%$ \\
\hline
\end{tabular}

The proportion of three provinces is listed in Table 8. Liaoning province is all over $40 \%$, Jilin province is about $25 \%$, Heilongjiang province is about $35 \%$. 
Table 8 The proportion of undergraduate students on campus in three northeast provinces (\%)

\begin{tabular}{|l|r|r|r|r|r|}
\hline Province & 2000 & 2005 & 2010 & 2015 & Changed in 15 years \\
\hline Liaoning & 44.05 & 41.02 & 41.06 & 42.37 & -1.68 \\
\hline Jilin & 25.89 & 25.34 & 25.39 & 26.66 & +0.76 \\
\hline Heilongjiang & 30.06 & 33.65 & 33.54 & 30.97 & +0.91 \\
\hline Total & 100 & 100 & 100 & 100 & - \\
\hline
\end{tabular}

\section{Summary}

This paper uses the data from China Statistics Yearbook, research on development of higher education in Northeast China. The result shows that, from 2000 to 2015, the higher education of Northeast China has improved a lot, but the growth speed is less than the whole country.

The number of universities and colleges in Northeast China has increased from 133 to 255; the number of university teachers has increased from 146640 to 237053; and the number of undergraduate students on campus has increased from 699096 to 2373524.

In the proportion of Northeast China to the whole country, the proportion of universities and colleges of Northeast China to the whole country has decreased from $12.78 \%$ to $9.96 \%$; the proportion of number of teachers has decreased from $13.18 \%$ to $10.01 \%$; and the proportion of number of undergraduate students on campus has decreased from $12.57 \%$ to $9.04 \%$.

In the comparison of the three northeast provinces, on the indicator of proportion of numbers of universities and colleges, teachers and undergraduate students on campus, Liaoning province always takes over $40 \%$ of Northeast China, Jilin province is about $25 \%$, and Heilongiiang province is about $35 \%$.

\section{Acknowledgements}

This research was supported by the University Basic Scientific Research Foundation of Department of Education of Liaoning Province "Research on the mechanism and countermeasures of enhancing teachers' sense of responsibility and improving teachers' professional ability (WY2016007)”.

\section{References}

[1] Information on https://en.wikipedia.org/wiki/Northeast_China

[2] N. Liu, L. Liu: Higher Education in Europe, Vol.30 (2005) No.1, p.217-227.

[3] Information on http://en.hit.edu.cn/.

[4] Information on http://en.jlu.edu.cn/.

[5] Information on http://en.dlut.edu.cn/.

[6] Information on http://english.neu.edu.cn/.

[7] L. Chen, Z. Wu, G. Huang, L. Zhou: Chinese Journal of Applied Ecology, 2002

[8] G. Nabi, W. Song, G. Ghous: International Journal of Service Science Management Engineering \& Technology, Vol.7 (2016) No.4, p.37-47.

[9] N. Consortium: New Media Consortium, Vol.24 (2015) No.4, p.311-334.

[10] Information on http://www.stats.gov.cn/. 